\title{
Notice
}

This is an Authors' Accepted Manuscript of an article published online 6 January 2014:

Kibler, E., Kautonen, T. and Fink, M. (2014). Regional social legitimacy of entrepreneurship: implications for entrepreneurial intention and start-up behaviour. Regional Studies, 48(6), 995-1015. (C) Taylor \& Francis

Changes introduced as a result of copy-editing, formatting and other publishing processes may not be reflected in this document. For a definitive version of this work, please refer to the published source: http://dx.doi.org/10.1080/00343404.2013.851373.

\section{Regional social legitimacy of entrepreneurship: implications for entrepreneurial intention and start-up behaviour}

\begin{abstract}
This article develops a new understanding of the role of regional culture in the emergence of business start-up behaviour. The focal construct is regional social legitimacy: the perception of the desirability and appropriateness of entrepreneurship in a region. The econometric analysis utilizes a combination of bespoke longitudinal survey data from 65 regions in Austria and Finland, and variables capturing regional socio-economic characteristics derived from official statistics. The study demonstrates that, and explains how, regional social legitimacy influences the relationships between individual entrepreneurial beliefs, intentions and start-up behaviour and how these interaction effects are conditioned by the socio-economic characteristics of the region.
\end{abstract}

Keywords: social legitimacy, entrepreneurship, institutions, culture, region, psychology

JEL classifications: B52, M13, R11 


\section{INTRODUCTION}

Research on the regional dimension of entrepreneurship complements the traditional focus on the individual in entrepreneurship research by demonstrating the crucial role entrepreneurship plays in regional development (FRITSCH and MUELLER, 2004; MUELLER et al., 2008; VAN STEL and STOREY, 2004). It also identifies a range of regional features that influence entrepreneurial activity at the individual level (ARMINGTON and ACS, 2002; FRITSCH and FALCK, 2007; REYNOLDS et al., 1994). In addition to the demographic, structural and economic characteristics of regions, scholars have increasingly devoted attention to investigating the role of the regional culture as a determinant of entrepreneurship (DAVIDSSON and WIKLUND, 1997; FRITSCH and WYRWICH, in this issue; AOYAMA, 2009). The results of this nascent stream of research highlight the impact of regional cultural factors, especially in the early stages of new firm formation (BOSMA and SCHUTJENS, 2011; LAFUENTE et al., 2007; VAILLANT and LAFUENTE, 2007).

This article adds to our knowledge of the influence of regional culture on individual entrepreneurial activity by focussing on the early stages of founding a new business: the formation of an intention to engage in starting a business and the subsequent translation of that intention into action (KAUTONEN et al., 2015). More specifically, this study proposes that the regional social legitimacy of entrepreneurship - understood as a convergence of perceptions in a region that entrepreneurial activity is 'desirable, proper or appropriate' (SUCHMANN, 1995: 574) - reflects a core element of a region's entrepreneurship culture (ETZIONI, 1987; FRITSCH and WYRWICH, in this issue) and shapes the way an individual's entrepreneurial beliefs influence the intention to start a business and the likelihood of the individual turning that intention into action. The hypothesis development builds upon the psychological foundations laid by the theory of planned behaviour (AJZEN, 
1991), which is complemented with institutional approaches to sociology (SCOTT, 1995; GREENWOOD et al., 2011), economic geography (GERTLER, 2010; RODRIQUEZ-POSE, 2013) and regional entrepreneurship (LAFUENTE et al., 2007; LANG et al., 2013). The hypotheses are tested with two waves of survey data on working-age individuals (wave $1=$ 2025; wave $2=984$ ) from 65 regions in Austria and Finland. In order to advance the assessment of the regional knowledge base of social legitimacy that we develop in this research, we test a series of models where each hypothesised relationship is interacted with a set of regional socio-economic factors suggested in the previous literature.

This research makes a number of contributions to the interface between regional studies and entrepreneurship. First, the study adds significant new empirical knowledge to our limited understanding of how regional social norms affect the formation of entrepreneurial intentions (LIÑÁN et al., 2011) and of how regional features influence the translation of intentions into start-up behaviour (KIBLER, 2013). As such, the study further emphasises entrepreneurship as a place-dependent (LANG et al., 2013) process of emergence (STERNBERG, 2009) and responds to the call for longitudinal and multi-level research to establish causality and uncover the mechanisms through which regional social norms influence new firm formation (BOSMA and SCHUTJENS, 2011).

Second, this study introduces the concept of the regional social legitimacy of entrepreneurship, and develops and validates a corresponding measurement instrument. Hence, this study addresses the lack of congruent concepts and measurement tools for the investigation of the regional cultural embeddedness of entrepreneurship (BOSMA et al., 2008; TRETTIN and WELTER, 2011). Complementing the regional legitimacy concept and design with a psychological approach, we most notably provide a new understanding of how 
the impact of high (or low) levels of social legitimacy on an individual's entrepreneurial beliefs, intentions and actions varies depending on the regional socio-economic environment. Consequently, we critically develop the - often self-evidently used - argument that social legitimacy increases the demand for entrepreneurship (ETZIONI, 1987) by offering a more nuanced regional knowledge base that explains (1) which entrepreneurial beliefs are (not) supported by social legitimacy in a particular regional context and (2) under what regional conditions social legitimacy strengthens (or weakens) the formation of entrepreneurial intention and its translation into start-up behaviour.

Third, based on the study, a number of regional implications for policy-makers and the enterprise community can be drawn regarding how they might promote entrepreneurship: In general, the regional social legitimacy of entrepreneurship has proven to be a feasible way of leveraging entrepreneurial intentions and action levels in a region. However, our findings reveal conditions that must be fulfilled in order for such interventions to be effective. Facilitating the formation of entrepreneurial intentions in a region through high levels of social legitimacy is only successful if the support measures explicitly address individuals' perceptions of entrepreneurship as a beneficial career path (entrepreneurial attitude). While this support is independent of the regional socio-economic context, measures that strengthen individuals' beliefs that they are 'fit' for entrepreneurship (perceived entrepreneurial ability), achieved via regional social legitimacy, are especially effective in rural regions. Interventions that strive to increase the likelihood of intentions turning into start-up behaviour by enhancing the social legitimacy of entrepreneurship are most suited to economically 'disadvantaged' regions. In regions where individuals perceive the social legitimacy of entrepreneurship as low, the translation of entrepreneurial intentions into actions can be supported by measures 
that help to build individuals' confidence that they are capable of starting and running businesses.

\section{THEORY}

Entrepreneurial intention and start-up behaviour

The conceptual foundation of the psychological processes leading to new firm formation is based on AJZEN's (1991) theory of planned behaviour (TPB). In the TPB, intention refers to 'a person's readiness to perform a given behavior' (AJZEN, 2011) and it is seen as the immediate antecedent of behaviour. A substantial amount of research in diverse behavioural domains demonstrates that intention is a good predictor of subsequent behaviour. Metaanalyses by ARMITAGE and CONNER (2001) and SHEERAN (2002) report mean correlations of 0.47 and 0.53 between intention and behaviour, respectively, and KAUTONEN et al. (2013 and 2015) demonstrate that the TPB accounts for 31-39\% of the variation in subsequent business start-up behaviour.

The formation of an intention is influenced by three antecedents: a favourable or unfavourable evaluation of the behaviour (attitude), beliefs concerning the expectations of important referent groups to perform or not perform the behaviour (subjective norm), and the perceived ability to perform the behaviour (perceived behavioural control, $\mathrm{PBC}$ ). $\mathrm{PBC}$ not only predicts the formation of intentions but, by serving as a proxy for actual control, also supports the prediction of actual behaviour (AJZEN, 1991). 
Regional social legitimacy of entrepreneurship

Social legitimacy in institutional theory

The theoretical foundation of the regional social legitimacy of entrepreneurship and its effects on entrepreneurial intentions and behaviour is anchored in institutional theory, which has been suggested to be an appropriate framework for examining the influence of both cultural and spatial contexts on entrepreneurial activity (WELTER, 2011). Institutional economic and sociological theories share the assumption that individual beliefs and behaviours are structured by the rules and norms prevalent in the institutional environment, while acknowledging that institutional contexts can enable and constrain individual behaviours, while also depending upon them (GIDDENS, 1984; NORTH, 1990; SCOTT, 1995; HODGSON, 2006). The understanding of institutions in the present study follows the sociological work of SCOTT (1995: 33), which defines institutions as 'social structures that have attained a high degree of resilience. [They] are composed of [three institutional pillars:] cultural-cognitive, normative, and regulative elements that, together with associated activities and resources, provide stability and meaning to social life'. The regulative pillar is understood to guide behaviour through the force of formal rules and sanctions; normative institutions guide behaviour through social norms of acceptability and morality; and the cultural-cognitive institutions guide behaviour through 'deeply entrenched assumptions and conceptions of the "way the world is"” (SCOTT, 2010: 7).

Reflecting SCOTT's (1995) framework, sociological institutional scholars often stress the role of social legitimacy in economic behaviour (e.g. ALDRICH and FIOL, 1994; DIMAGGIO and POWELL, 1983; see BITEKTINE, 2011 for an overview), emphasising a strong cultural dimension of legitimating processes and the social sanctions attached to them 
(BITEKTINE, 2011; DEEPHOUSE and SUCHMANN, 2008). While different theoretical constructs of social legitimacy have been developed, the concept is widely seen as 'a generalized perception or assumption that the actions of an entity are desirable, proper or appropriate' (SUCHMANN, 1995: 574). The present article's specific definition of social legitimacy reflects SCOTT's normative and cognitive institutional pillars, and particularly relies on SUCHMANN's (1995) conceptualisation, which involves three dimensions of social legitimacy: pragmatic, moral and cognitive legitimacy. Applied to the entrepreneurial context, pragmatic legitimacy reflects self-interested calculations concerning entrepreneurship; moral legitimacy relies on normative evaluations of entrepreneurship; and cognitive legitimacy rests on taken-for-granted assumptions of entrepreneurship, irrespective of a negative, a positive or no valuation. SUCHMANN (1995) further refined this framework with two substantive foci of legitimacy, which in this context, further distinguish between the perceived social legitimacy of what entrepreneurs do (action) and what values they represent (essence).

Regional perspective to social legitimacy

This study complements SUCHMANN's (1995) conceptualisation with an institutional perspective on economic geography and regional entrepreneurship, in order to emphasise the local dimension in the concept of social legitimacy. The extant literature contains a number of conceptualisations and empirical studies that provide direct or indirect information on social legitimacy as a regional phenomenon. For instance, GONZÁLES and HEALEY (2005) develop an institutional approach to regional economic activity that emphasises the role of the social meanings that individuals attach to the region in which they are embedded. OSTROM's (2005) institutional framework suggests that economic processes in a region must be 
understood in the context of the common attributes and norms of behaviour prevalent in the regional community. She further argues that certain informal rules-in-use reflect the social expectations of the 'do's and don'ts' (OSTROM, 2005: 832) in a regional community that sanction its members' choices and behaviour. Inspired by the work of HOLMÉN (1995) and MARTIN (2000), HAYTER (2004: 107) underlines that regions develop specific regionbounded 'values, processes of valuations [and] modes of thought' over time that arguably reflect the core elements of social legitimacy. RAFIQUI (2009: 341) highlights the regional variability of social norms by emphasising that "varying physical environments and historical experiences means that beliefs [and] institutions...differ between places'. Supporting this argumentation, GERTLER's (2010) and RODRIQUEZ-POSE's (2013) recent work on institutional theory in economic geography suggests that regions cultivate distinctive institutional contexts over time, which leads to various social evaluations of economic activity.

In a similar vein, THORNTON and FLYNN (2003) and LANG et al. (2013) conclude that the geographic environment for entrepreneurial activity needs to be understood based on the social boundaries of local communities, reflecting the cognitive and culture-based shared meanings and valuations amongst the members of the community. Encapsulating SCOTT's view with a local perspective, MARQUIS and BATTILANA (2009: 294) further theorise 'that local communities are institutional arenas that have an enduring influence on organizational behaviour through regulative, normative, and cultural-cognitive processes'. These processes, in turn, are encoded in 'local' rules that are reflected in everyday expectations and practices, potentially affecting how members of the regional community perceive the social value of economic behaviours (GREENWOOD et al., 2011; LANG and ROESSL, 2011). In line with ETZIONI's (1987) theorisations, the social legitimacy of 
entrepreneurship reflects one important aspect of the cultural and normative environment, which can support or hinder the emergence of entrepreneurial activity across different geographical contexts. Drawing upon these foundations, this study understands regional social legitimacy as the perceived normative rules-in-use concerning a particular behaviour in a regional community, which reflect the local understandings and beliefs concerning the social acceptance of that behaviour.

\section{Influence of regional social legitimacy of entrepreneurship on new firm formation}

While the concept of the regional social legitimacy of entrepreneurship is novel, prior studies provide indirect evidence on its relevance in the early stages of the firm formation process. For instance, DAVIDSSON and WIKLUND (1997) suggest that the prevalence of certain socio-cultural values affects regional levels of new firm formation. BOSMA and SCHUTJENS (2011) demonstrate that informal institutions at the regional level can play a stronger role in shaping entrepreneurial attitudes and behaviour than national institutional contexts. In addition, previous institutional entrepreneurship studies commonly suggest social acceptance of business failure and the presence of entrepreneurial role models in a region are potentially socio-cultural forces that influence early-stage entrepreneurship (LAFUENTE et al., 2007; VAILLANT and LAFUENTE, 2007). As such, the recent literature highlights the importance of examining social values and norms affecting enterprising activity in a regional context. However, few studies address how specific regional cultural norms influence the psychological processes leading to the emergence of new firms.

To the best of our knowledge, the only study to date that explicitly examines the cognitive mechanisms underpinning business start-up intentions in a regional cultural context is that by 
LIÑÁN et al. (2011), which combines an institutional approach with the TPB and shows that the influence of perceived societal values on individual entrepreneurial beliefs differs significantly between the two Spanish regions examined. Their study further proposes that examining the moderating role of the regional socio-cultural environment on entrepreneurial beliefs adds to the knowledge of how entrepreneurial intentions emerge. This concurs with the recent findings of KIBLER's (2013) study, which demonstrate that different demographic, economic and structural features of a region can moderate the impact of entrepreneurial beliefs on the formation of entrepreneurial intention.

In addition to the aforementioned literature, the hypotheses in the present study are founded upon ETZIONI's (1987) and LIAO and WELSCH's (2005) investigations. ETZIONI (1987: 175) suggests that 'the extent to which entrepreneurship is legitimate, the demand for it is higher; the supply of entrepreneurship is higher; and more resources are allocated to the entrepreneurial function'. He adds that the 'acceptance of the risk taking involved will be much higher if entrepreneurship is legitimated' (ETZIONI, 1987: 186). LIAO and WELSCH (2005) further emphasise that social legitimacy plays a particular role in new firm formation as it facilitates access by potential and nascent entrepreneurs to social capital and other external resources. Following these reflections, the present study's main theoretical argument is based on the assumption that the more an individual perceives entrepreneurship as socially legitimatised in a region, the more likely she or he evaluates a regional environment as benevolent and munificent for entrepreneurial activity. Accordingly, we argue that the regional social legitimacy of entrepreneurship has a positive influence on the beliefs leading to the formation of entrepreneurial intentions and to their translation into start-up behaviour. 
Applying the regional interaction logic suggested by KIBLER (2013), we specifically propose that a higher degree of regional social legitimacy of entrepreneurship strengthens an individual's certainty in their entrepreneurial beliefs - entrepreneurial attitude, perceived social support and perceived entrepreneurial ability - which, in turn, affects how strongly those beliefs affect the formation of entrepreneurial intention. Similarly, we suggest that a higher level of regional social legitimacy, associated with a supportive and less risky environment for entrepreneurship (ETZIONI, 1987), can strengthen an individual's certainty of their intention and PBC, which increases the likelihood of intentions turning into action. Therefore, the specific research hypotheses offered for empirical testing are as follows:

Hypothesis 1: Regional social legitimacy of entrepreneurship strengthens the positive impact of (a) attitudes, (b) subjective norms and (c) PBC on entrepreneurial intentions.

Hypothesis 2: Regional social legitimacy of entrepreneurship strengthens the positive impact of (a) entrepreneurial intentions and (b) PBC on start-up behaviour.

Regional social legitimacy of entrepreneurship and the socio-economic context in the region

So far, the current study has hypothesised relationships that pertain to an individual's attitudes, perceptions, intentions and behaviours. This section outlines the argument that these relationships might vary depending on the specific socio-economic characteristics of the region where the individual lives. This argument is founded on recent studies that have emphasised the role of regional socio-economic factors in the nascent or pre-action phase of entrepreneurship (BOSMA and SCHUTJENS, 2011; KIBLER, 2013). However, since there is 
yet no direct evidence on the regional determinants of social legitimacy effects in the formation of entrepreneurial intention and its translation into start-up behaviour, this section omits formal hypotheses and instead, offers a discussion that draws upon the existing regional entrepreneurship knowledge and provides a conceptual base to complement and assess the main hypotheses outlined above.

The literature suggests that urban, highly populated regions tend to support business start-up processes by providing more accessible market opportunities and entrepreneurial resources than rural, sparsely populated areas (KEEBLE and WALKER, 1994; REYNOLDS et al., 1994; TÖTDLIG and WANZENBÖCK, 2003). Often associated with urban contexts, a greater number of well-educated people in a region has often been found to raise entrepreneurial activity levels (ARMIGTON and ACS, 2002; AUDRETSCH and FRITSCH, 1994; BOSMA et al., 2008). This is perhaps due to higher levels of creativity and innovation in the region (LEE et al., 2004) and more established local, entrepreneurial networks (MAILLAT, 1995). When accompanied by higher education levels, 'younger' regional age compositions tend to induce a greater local potential of (high-growth) entrepreneurship (BOSMA et al., 2009; BOSMA and SCHUTJENS, 2011), supported by the finding hat (nascent) entrepreneurial activity levels are particularly high amongst people aged 25-44 (REYNOLDS, 1997; PARKER, 2009). Subsequently, regional demographic characteristics also reflect how entrepreneurship is socially valued in the region (MARQUIS and BATTILANA, 2009), through co-determining the local availability of and access to entrepreneurial opportunities, networks and capital (AUDRETSCH and KEILBACH, 2004). In line with the evidence presented, regions with a high population density and a larger pool of young, well-educated workers may particularly strengthen local beliefs that entrepreneurship is appropriate and taken-for-granted, thus potentially conditioning the 
influence of social legitimacy on an individual's intention formation and start-up behaviour in the region.

Regional economic and labour market characteristics may also influence the way social legitimacy affects entrepreneurial intentions and actions. Previous research suggests that regions with higher income and wealth levels tend to provide favourable conditions for entrepreneurship. This influence has been ascribed to an increased spending capacity, higher demand for products, a greater supply of resources for business capitalisation and lower borrowing costs (STAM, 2010). However, higher regional economic levels can make paid employment comparatively more attractive (BOSMA et al., 2008) and potentially reflect the higher opportunity costs of becoming an entrepreneur in the region (ASHCROFT et al., 1991). In addition, higher unemployment rates can indicate a lower demand for new businesses in the region (REYNOLDS et al,. 1994), but at the same time can increase the proportion of people being pushed towards entrepreneurship (AUDRETSCH and FRITSCH, 1994; BOSMA and SCHUTJENS, 2011). Furthermore, regions with a large share of service sector employment might indicate lower average business foundation costs (FRITSCH, 1997). Thus, contrary to the cost intensive manufacturing sector, skills and educational references are the key to starting a business in a region dominated by the service sector (BRIXY and GROTZ, 2007). Such regions offer a local environment with more room to discover and exploit entrepreneurial opportunities (VAN STEL and STOREY, 2004). Accordingly, economic and labour market characteristics are relevant regional conditions for the emergence of entrepreneurship (STERNBERG, 2009), which in turn may relate to the extent to which regional social legitimacy affects the entrepreneurial process. 
The previous research suggests that higher regional entrepreneurship levels in the past serve as an ongoing conduit for a positive entrepreneurial climate (ANDERSON and KOSTER, 2011), for instance, through increased innovation activities, knowledge spillovers, competition and firm diversity (AUDRETSCH and KEILBACH, 2004; FRITSCH and MUELLER, 2007). Moreover, higher levels of entrepreneurial activity can provide positive role models through showcasing successful firm formation stories (VAILLANT and LAFUENTE, 2007), which can foster local entrepreneurial learning processes (SORENSONIA and AUDIA, 2000) and thus the development of local perceptions favourable to entrepreneurship (FORNAHL, 2003; MINNITI, 2005). To this FRITSCH and WYRWICH's (in this issue) recent study adds that the establishment of a persistent regional entrepreneurship culture is rooted in higher entrepreneurial activity levels in certain periods in the past. Against this backdrop, higher business start-up rates help create a positive entrepreneurial climate in the region, thus arguably strengthening any recent influence on entrepreneurial beliefs and start-up behaviour exercised by the regional social legitimacy of entrepreneurship.

In summary, the available evidence suggests that demographic, economic, labour market characteristics and also past business start-up levels can have implications for individual enterprising activity. To what extent these socio-economic factors condition the way the regional social legitimacy of entrepreneurship influences the psychological processes that lead to the formation of entrepreneurial intentions and their subsequent translation into start-up behaviour is an empirical question in this study. Figure 1 provides a summary of the relationships that will be examined in the following empirical analysis.

\section{INSERT FIGURE 1 ABOUT HERE}




\section{DATA AND VARIABLES}

\section{Data collection}

The survey was conducted in two waves (in 2011 and 2012) in Austria and Finland by means of a postal survey targeting the working-age population (20-64 years old). Two countries were included in the research design in order to examine the robustness of the findings across different national environments.

In the first wave, 10,000 questionnaires were distributed in Finland and 15,000 in Austria. The questionnaires were sent to randomly selected respondents in a representative range of regions according to a strategy devised in consultation with statisticians at the Finnish Population Register Centre and Statistics Austria. The regions were selected randomly from a pool of 146 Austrian (population $>5000$ ) and 193 Finnish municipalities (population $>3000$ ) following a stratified sampling logic to ensure that the choice of municipalities represented different regional cultures and the three municipality types: urban, semi-urban and rural (STATISTICS AUSTRIA, 2011a; STATISTICS FINLAND, 2011). The resulting Austrian sample comes from 27 municipalities of which nine are urban, nine semi-urban and nine rural, while the Finnish sample encompasses 38 municipalities of which 14 are urban, 12 semiurban and 12 rural. Figures 2 and 3 present the sample regions on country maps. Further details of the regional sampling logic are available from the authors upon request.

\section{INSERT FIGURES 2 AND 3 ABOUT HERE}

The postal survey produced 2263 responses in Finland and 1024 responses in Austria. Thus, the respective response rates were $23 \%$ and $7 \%$. The difference in response rates is partly 
explained by cultural factors (the research team's prior experience suggests that response rates in Austria are much lower than in Finland) and partly by differences in the sampling approach. The Finnish research team could derive an exactly specified sample with up-to-date addresses from the Population Register Centre, while the Austrian team had to apply a heuristic approach based on names and addresses derived from an online phone book. While applying regional weighting, ensuring a gender balance and maintaining the random sampling logic were unproblematic in both countries; the Austrian task was less efficient because of outdated address information that resulted in 1519 undeliverable mailings and a lack of ex ante information on people's ages. As a result, many of the responses received were from people outside the specified age range. Therefore, the actual usable sample of 766 Austrian individuals between 20 and 64 years of age is considerably smaller than the initial sample of 1024 individuals.

Since this article concerns entrepreneurial intentions and their subsequent translation into start-up behaviour, individuals who were already self-employed in 2011 (18\% of the total sample) were excluded from the analysis, leaving 2446 eligible observations ( $23 \%$ Austrian). Furthermore, 421 cases had to be deleted because of an excessive number of missing responses, which would have compromised the validity of the multi-item indices. A comparison of the demographic characteristics of the final sample of 2025 cases with the sample of 2446 eligible cases suggests that the exclusions on the grounds of missing responses have not introduced a notable demographic bias to the data.

The second wave of data collection included all eligible respondents in the final first-wave Austrian sample and those Finnish respondents who were included in the final first-wave sample and who had given their permission to be contacted in a follow-up study. 
Consequently, researchers distributed 1002 questionnaires in Finland and 455 in Austria by post. Subjects from Finland, who had not responded within three weeks, were sent a reminder by post. In Austria, prior experience indicated that telephone calls would be the more effective follow-up method. This process resulted in 732 responses in Finland (response rate: 73\%) and 252 in Austria (response rate: 55\%).

\section{Non-response bias}

The current research adopts an archival analysis approach to examining non-response bias (ROGELBERG and STANTON, 2007). Accordingly, the Finnish first-wave sample of 1570 respondents was compared with the original list of 10,000 randomly selected individuals received from the Population Register Centre; similarly, the Austrian first-wave sample of 455 respondents was compared with an officially available list of the age and gender distribution supplied by STATISTICS AUSTRIA (2011b). The comparison shows that the average ages of the respondents in the sample are the same as the national averages in the age group 20-64 (44 in Finland, 42 in Austria). Finnish women have a higher comparative participation rate than Finnish men, since $60 \%$ of the respondents in the Finnish sample are women, compared with $49 \%$ in the original list. The Austrian sample, on the other hand, has an almost even gender distribution with $51 \%$ of respondents being women. Within the municipality types of urban, semi-urban and rural, the response rates range from $22 \%$ to $24 \%$ in Finland and from $6 \%$ to $8 \%$ in Austria. Thus, there is no notable regional type bias in the sample.

In the second-wave sample, the average age was 44 in both countries and the proportion of women in the sample was $62 \%$ in Finland and $55 \%$ in Austria. The distribution of the 
respondents across the three region types is nearly identical in the first and second survey waves. Hence, the most notable bias appears to be the over-representation of women in both waves of the Finnish sample. However, since the purpose of this research is to test theoretical relationships rather than provide representative descriptive statistics, minor differences between the sample and the population are not expected to exert a major influence on the analysis.

\section{Variables}

Theory of planned behaviour

Intention, behaviour, attitude, subjective norms and $\mathrm{PBC}$ were operationalized by referring to AJZEN's (2011) instructions and previous empirical work applying the TPB in the entrepreneurial context (KAUTONEN et al., 2015; KOLVEREID, 1996; SOUITARIS et al., 2007). Each construct was measured with multiple items using six-point rating scales (Appendix 1). Following AJZEN (2011), all items refer to the same behaviour (engaging in activities to start a business) and the same time frame (within the coming 12 months). After factor-analysing the multi-item scales (see below), composite indices were computed for all constructs by averaging the relevant items. The Cronbach's alpha scores for the five indices range from .81 to .94 .

Regional social legitimacy of entrepreneurship

The regional social legitimacy of entrepreneurship is operationalized in line with SUCHMANN's conceptualisation (1995) and includes three sub-scales of legitimacy practical, moral and cognitive - with each scale comprising two underlying foci - actions and essences (Appendix 1). The practical legitimacy sub-scale measures whether an individual 
perceives the activity of entrepreneurs in their region to be beneficial for themselves (action) and the values held by local entrepreneurs to be similar to their own (essence). The cognitive legitimacy sub-scale reflects taken-for-granted assumptions, measuring the degree to which an individual views the activity of local entrepreneurs as necessary (action) and the absence of entrepreneurs in their region as inconceivable (essence). The moral legitimacy sub-scale indicates whether an individual perceives local entrepreneurs as trustworthy and operating according to the common norms in their region (essence) as well as contributing to the local economy (action) and social well-being of all local people (action). Thus, the final index capturing the regional social legitimacy of entrepreneurship consists of seven items (Cronbach's alpha: .85).

Regional socio-economic characteristics

In line with our theoretical reasoning, eight regional socio-economic sets of data were selected from the databases of Statistics Finland (2013) and Statistics Austria (2013). While the required data were fully accessible through the publicly available databases of Statistics Finland, specific access and assistance was required from Statistics Austria (2013), to guarantee an accurate secondary regional data collection process in both countries. The description of the regional socio-economic variables is depicted in Table 1.

\section{INSERT TABLE 1 ABOUT HERE}

\section{Covariates}

The regression models include several covariates at the individual and regional levels. The first one of the four individual-level covariates is a dummy indicating whether the individual 
is female or male, which controls the potential effect of the common and consistent finding of a lower entrepreneurial propensity among women (XAVIER et al., 2013). The second one is the respondent's age in years in a quadratic specification, which adjusts the models for the well-known inverse U-shaped effect of age on entrepreneurial activity (LÉVESQUE and MINNITI, 2006). Third, a dummy variable, measuring whether the respondent has (never) started a business in the past, controls for the influence of previous entrepreneurial experience, which has been found to be an important influence in the TPB context (CONNER and ARMITAGE, 1998). The fourth individual-level covariate is the respondent's perception of the local acceptance of business failure (LAFUENTE et al., 2007; VAILLANT and LAFUENTE, 2007). This variable is measured with a six-point rating scale inquiring the extent to which the respondent thinks that entrepreneurs who fail in their business are frowned upon by local people. At the regional level, the analysis controls for the impact of the type of region (urban, semi-urban and rural) (BOSMA et al., 2008; STAM, 2010), as well as the country the region is in.

\section{Factor analysis}

Before index scores were computed, the multi-item measurement scales (Appendix 1) were factor analysed. Since the exploratory principal components analysis did not indicate a need to remove items, a confirmatory factor analysis (CFA) was performed in order to subject the factor structure to a stringent test. The CFA was estimated separately for the first-wave and second-wave Finnish and Austrian sub-samples. All indicators loaded on their intended constructs with the $.1 \%$ significance level. The conventional fit indices suggested an acceptable fit between the model and the data according to the criteria proposed by HU and BENTLER (1999) for maximum likelihood estimation: the comparative fit index (CFI) $\geq .95$ 
(Austria: first wave .96/second wave .95; Finland: .96/.96), the root mean square error $($ RMSEA) $<.06$ (Austria: .054/.058; Finland: .055/.050) and the standardised root mean squared residual $($ SRMR) $<.08$ (Austria: .043/.051; Finland: .037/.042). Models using the full sample including respondents from both countries result in similarly satisfactory fit indices in both waves (CFI: .96/.97, RMSEA .051/.046 and SRMR: .033/.038). Therefore, the analysts concluded it was safe to compute indices for each construct by averaging the item scores.

\title{
Descriptive statistics
}

Table 2 presents the descriptive statistics for the survey data including a comparison of the first and second survey waves. Table 3 displays the correlation matrix for the continuous and binary variables in the survey data. Some of the intercorrelations are relatively high. However, the variance inflation factor (VIF) scores are moderate (with a mean of 2.9) and thus do not suggest the presence of serious multicollinearity.

\section{INSERT TABLES 2 AND 3 ABOUT HERE}

\begin{abstract}
ANALYSIS
Model specification

The data used in this analysis contain two levels: the individual and the regional. In addition to the data containing independent variables at both levels (the dependent variables are both measured at the individual level), the individual responses are not independent because they are clustered in the 65 municipalities included in the analysis. The hierarchical structure of the data has two important consequences for econometric strategy. First, the clustering of
\end{abstract}


individual responses in the 65 municipalities means that residual errors may not be independently distributed. As a result, the analysis had to address the Moulton problem arising from the clustered nature of the data, as it could affect the reliability of the standard error estimates (ANGRIST and PISCHKE, 2009). Second, in order to examine the extent to which the effect of social legitimacy varies regionally, the analysis required information on its variance across the 65 municipalities.

These requirements dictated that the econometric technique of choice would be multilevel regression. This technique not only solves the Moulton problem of clustered data by distinguishing between the individual-level and regional-level error components, it also provides information on the variance of the effect of social legitimacy across regions by allowing the effect to vary at the regional level (HOX, 2010).

The research design includes two dependent variables: intention to engage in activities aimed at starting a business and subsequent behaviour. A series of model specifications pertaining to each will be estimated. The principal econometric model is given by

$$
y_{i j}=\alpha_{j}+\beta_{1} x_{l i j}+\cdots+\beta_{k} x_{k i j}+\gamma_{1} z_{l j}+\cdots+\gamma_{q} z_{q j}+u_{j}+v_{j} x_{S L i j}+\varepsilon_{i j}
$$

In Eq. (1), the variable $y_{i j}$ represents the level of intention or behaviour for an individual $i(i=$ $1, \ldots, n)$ who lives in region $j(j=1, \ldots, 65)$. The symbols $x_{l i j}, \ldots, x_{k i j}$ denote individual-level variables, $z_{l j}, \ldots, z_{q j}$ are the regional-level variables, and $\beta_{1}, \ldots, \beta_{k}$ and $\gamma_{1}, \ldots, \gamma_{q}$ stand for the respective coefficients. The residual error terms for the intercept $\left(u_{j}\right)$ and the coefficient of social legitimacy $\left(v_{j} x_{S L i j}\right)$ measure region-specific effects that are not included in the model 
and thus control for unobserved heterogeneity across regions. The symbol $\varepsilon_{i j}$ denotes the individual-level residual error.

\section{Estimations of unconditional effects}

The first stage of analysis estimated a series of model specifications containing the unconditional effects of the explanatory variables and covariates on both dependent variables to provide a foundation for subsequent testing of the conditional hypotheses involving interaction effects. Initially, intercept-only models were estimated for intention and behaviour using random-intercept regression with maximum likelihood estimation. Those estimations show non-significant variance components for both dependent variables, implying that the variability in the levels of intention and behaviour does not depend on the regional clustering of the data.

The next model specification included the individual's perception of the regional social legitimacy of entrepreneurship as the sole predictor. Its effect on intention was positive and significant at the $1 \%$ level (coefficient: .11, z-statistic: 3.22 ), while the effect on behaviour was not significant (coefficient: .04, z-statistic: 1.29). Adding a random slope to the equation did not improve the fit of the model in either case (intention: $\chi_{2 \mathrm{df}}^{2}=.40$; behaviour: $\chi_{2 \mathrm{df}}^{2}=$ 1.31. As a result, the remaining model specifications do not include a random coefficient for social legitimacy. However, despite the lack of significant regional variability in intention and behaviour suggesting that a multilevel design is not necessary for these data, the analysis retains the random-intercept modelling logic owing to the model including variables at the regional level (Eq. 1). 
The full unconditional model estimations for intention and behaviour are displayed in Table 4 . The results support the relevance of the TPB in the entrepreneurial context: attitude, subjective norms and $\mathrm{PBC}$ are positive and significant predictors of intention, while intention and PBC predict subsequent behaviour.

\section{INSERT TABLE 4 ABOUT HERE}

\section{Hypothesis tests}

The hypotheses $\mathrm{H} 1(\mathrm{a}, \mathrm{b}, \mathrm{c})$ and $\mathrm{H} 2(\mathrm{a}, \mathrm{b})$ propose that the relationships in the TPB are conditional on the perceived level of regional social legitimacy of entrepreneurship. Testing these hypotheses requires the estimation of multiplicative interaction effects. Hence, interaction terms were formed by multiplying attitude, subjective norms, $\mathrm{PBC}$ and intention with social legitimacy. The relevant interaction terms were added to the model specifications presented in Table 4. After estimating each model, the marginal effects of the TPB predictors were computed when social legitimacy is set to one and two standard deviation units below and above its mean. This article omits the full results tables, since the standard regression output provides little information useful for understanding conditional marginal effects when the interaction involves continuous variables (BRAMBOR et al., 2006). While graphing the interaction effects is customary, this analysis tabulates the results, which permits the efficient presentation of multiple interactions.

INSERT TABLE 5 ABOUT HERE 
The estimations in Table 5 show that the effect of attitude on intention and, the effect of intention on behaviour, become stronger when the level of social legitimacy increases. While the effects of subjective norms and $\mathrm{PBC}$ on intention are unaffected by the level of social legitimacy, PBC exerts a positive and significant impact on behaviour only when social legitimacy is below its sample mean. In short, these findings support H1a, but not H1b and H1c. The results further support $\mathrm{H} 2 \mathrm{a}$ and do find a significant, but opposite effect of PBC on entrepreneurial action as proposed in $\mathrm{H} 2 \mathrm{~b}$.

\section{Sensitivity analysis: interactions with regional characteristics}

In order to assess the influence of regional socio-economic features on the relationships estimated thus far, the analysis proceeded with the estimation of a series of models where each relationship in Table 5 is further interacted with the eight regional variables depicted in Table 1 (e.g., attitude*social_legitimacy*population_density). Each interaction was estimated separately in order to facilitate interpretation and each model estimated includes the full list of variables displayed in Table 4. The marginal effects of the TPB predictors were computed with social legitimacy and the regional variable in question, each set one standard deviation unit below and above their means, resulting in four marginal effects estimated for each relationship in the TPB (Table 6). A verbal summary of the main results based on Tables 4, 5 and 6 is presented in Table 7. The interpretation of the three-way interactions between the TPB predictors, regional social legitimacy of entrepreneurship and socio-economic features of the region, depicted in the third column of Table 7 , focuses on how the regional variables influence the effect of social legitimacy on the relationships in the TPB, rather than on how the regional variables modify the effects of the TPB predictors on intention and behaviour. 


\section{INSERT TABLE 6 AND TABLE 7 ABOUT HERE}

\section{DISCUSSION AND CONCLUSION}

This study is an initial attempt to examine the conditioning effect of the regional social legitimacy of entrepreneurship on the relationships laid out in the TPB (AJZEN, 1991), which lead to the formation of entrepreneurial intentions and their subsequent translation into startup behaviour. Complementing the TPB with institutional approaches to sociology (SCOTT, 1995), economic geography (GERTLER, 2010) and regional entrepreneurship (LAFUENTE et al., 2007), we defined the regional social legitimacy of entrepreneurship as a convergence of beliefs in a region that entrepreneurial activity is 'desirable, proper or appropriate' (SUCHMANN, 1995: 574). We argued that the regional social legitimacy of entrepreneurship influences the degree to which a region provides a beneficial environment for the emergence of enterprising behaviour (ETZIONI, 1987).

Based on two waves of survey data on working-age individuals (wave $1=2025$; wave $2=$ 984) from 65 regions of Austria and Finland, our econometric analysis provides strong evidence that the emergence of an entrepreneurial intention and its impact on subsequent start-up behaviour depends on the perceived regional social legitimacy of entrepreneurship. A regional sensitivity analysis utilising regional-level variables derived from the official national statistics in Austria and Finland further demonstrates that certain effects of social legitimacy on intention formation and action initiation are conditioned by demographic, economic and labour market features of, and past entrepreneurial activity levels in, the region. The sensitivity analysis thus complements our understanding of the role of the perceived social legitimacy of entrepreneurship in a region by accounting for the conditioning effects of socio-economic regional characteristics suggested in the previous literature. 
In particular, the study's findings suggest that the more entrepreneurship is considered a socially legitimate activity in a region, the stronger will be an individual's entrepreneurial attitudes that form their intention to become an entrepreneur. Thus, following the regional interaction logic applied here (KIBLER, 2013), an individual's certainty that entrepreneurship is a beneficial career path (attitude) increases when they are embedded in a region where entrepreneurial activity is morally accepted or taken-for-granted, and this certainty in turn strengthens their entrepreneurial intentions. The results further show that the social legitimacy effect on the attitude-intention relationship is unaffected by the regional socio-economic factors included in the sensitivity analysis. Accordingly, the study extends the work of BOSMA and SCHUTJENS (2011), which emphasises that certain local norms and socioeconomic factors enhance the emergence of entrepreneurial attitudes by suggesting that the strength with which these attitudes support the formation of intentions is conditioned by the regional social legitimacy of entrepreneurship and independent from regional socio-economic factors.

Counter to our assumption, the findings illustrate that the regional social legitimacy of entrepreneurship does not affect how perceived social support from family and friends (subjective norms) influences an individual's intentions to start a business. The non-effect of social legitimacy on the relationship between subjective norms and intentions is robust in the face of regional socio-economic factors. It seems that, when they derive approval and support for enterprising activity from their close social environment, individuals consider it less necessary to seek approval from the residual local environment when developing entrepreneurial intentions. Thus, in this context, the influence of regional social legitimacy is negligible. 
Our findings further suggest that the impact of perceived entrepreneurial ability (PBC) on entrepreneurial intentions becomes stronger when entrepreneurship enjoys a higher degree of regional social legitimacy. However, this is only the case in regions with higher business entry rates in the past, and lower levels of population density, education, unemployment, GRP and service sector employment, which arguably reflects the conditions often present in peripheral, rural areas. This implies that a local cultural environment supporting entrepreneurship becomes particularly relevant for strengthening an individual's perception that they are able to run a successful business, in rural regions with a limited local stock of financial and human capital (OECD, 2006). In addition, the identified positive influence of high business entry rates on social legitimacy provides new empirical evidence of how prior entrepreneurial activity can strengthen an entrepreneurship-friendly culture (AUDRETSCH and KEILBACH, 2004), particularly in rural areas (LAFUENTE et al., 2007). Accordingly, we conclude that individuals embedded in rural areas are particularly reliant on approval from the regional cultural environment, supported by accounts of successful firm formation (VAILLANT and LAFUENTE, 2007), when developing their entrepreneurial intentions, because such a climate fosters their confidence in having control over their successful start-up behaviour (LANG et al., 2013).

Moreover, the empirical analysis provides prima facie evidence that high levels of regional social legitimacy enhance the impact of intentions on the likelihood of an individual subsequently engaging in start-up behaviour. This finding emphasizes that an individual's perception of high regional social legitimacy strengthens their expectation of receiving social capital (LIAO and WELSCH, 2005) and positive social feedback from the regional community when turning intentions into entrepreneurial action. The analysis further suggests 
that this is of particular relevance for aspiring entrepreneurs needing to overcome potential entrepreneurial obstacles in economically 'disadvantaged' regions. In other words, the local community's support and supply of resources for aspiring entrepreneurs is likely to be greater if entrepreneurship is highly socially legitimate (ETZIONI, 1987). This in turn can compensate for economic restrictions in the local environment and can give those with entrepreneurial intentions the final impulse needed to turn their intentions into actual start-up behaviour.

However, high levels of regional social legitimacy for entrepreneurship do not always foster the transformation of intentions into action. Our study also uncovers regional configurations where the likelihood of an individual moving from entrepreneurial intention to actual start-up behaviour decreases with a higher degree of regional social legitimacy of entrepreneurship. More specifically, when regions show high GRP levels, high prior GRP growth rates, a high proportion of people aged 25-44 and low prior entrepreneurial activity levels, the positive impact of entrepreneurial intention on entrepreneurial behaviour becomes weaker with high levels of regional social legitimacy. We argue that relatively wealthy regions with a large proportion of younger individuals in their populations might establish entrepreneurshipfriendly cultures, but at the same time high salaries imply high opportunity costs for employees in becoming entrepreneurs (ASHCROFT et al., 1991). The high opportunity costs of entrepreneurship seem to undermine the positive effects of high regional social legitimacy, with the result that entrepreneurial intentions are less likely to be translated into action.

The results further emphasize that the role of an individual's perceived entrepreneurial ability in the taking of entrepreneurial action is more important in regions where entrepreneurship is less socially legitimate. If potential entrepreneurs perceive entrepreneurship as possessing low 
social legitimacy in their region, they might anticipate having only limited access to local social capital, meaning that the final step from intention to actual establishment of a firm will require a strong belief in their own entrepreneurial capabilities.

\section{IMPLICATIONS}

Overall, this study supports the proposition that the regional social normative context influences entrepreneurial cognitions and the emergence of individual entrepreneurial activity. The empirical findings further suggest that the implications of regional cultural norms for entrepreneurship (partly) relate to different stages of the entrepreneurial process at the individual level and to different socio-economic contexts at the regional level. This underlines the importance of longitudinal and multilevel designs in regional entrepreneurship research. The large body of previous regional studies provides useful insights into the effects of the demographic, economic, regulative and industry features of a region. However, this research suggests that the development of a location-sensitive institutional understanding (LANG et al., 2013) of the social norms that facilitate individual entrepreneurial activity can complement and enrich the body of knowledge on regional influences on entrepreneurship. Moreover, the conceptualization and operationalization of the regional social legitimacy of entrepreneurship developed and tested in this study provides a novel and valid conceptual and empirical instrument for measuring a major determinant of a regional entrepreneurship culture (FRITSCH and WYRWICH, in this issue) and its impact on entrepreneurial cognitive processes and start-up behaviour.

The main policy implication of this study is that the perceived regional social legitimacy of entrepreneurship clearly matters in the early stages of an individual's firm formation process. As such, the regional understanding of social legitimacy developed in this paper can serve as 
one important measure by which policy makers and the enterprise support community can improve regional entrepreneurship levels. We suggest that, independent of the regional socioeconomic context, an increased regional social legitimacy of entrepreneurship could help policy makers to mobilize the formation of entrepreneurial intentions in a region, by influencing individuals' entrepreneurial attitudes. The findings further imply that (institutional) actors involved in rural entrepreneurship support need, above all, to create an environment that socially approves entrepreneurial activity in order to strengthen individuals' confidence and the perceived ability to run a business in a rural area; this, in turn, will facilitate higher entrepreneurial intention levels. Moreover, fostering the regional social legitimacy of entrepreneurship should play a crucial role in helping with the design of effective entrepreneurship support initiatives in economically 'disadvantaged' regions, by increasing the likelihood that individuals will not only hold entrepreneurial intentions, but also turn them into actual start-up behaviour. The study further suggests that, independent of a region's socio-economic composition, policy makers need to focus particularly on supporting individuals' perceived entrepreneurial ability in order to enhance the critical translation of entrepreneurial potential into entrepreneurial activity in regions with - temporarily - lower levels of social legitimacy of entrepreneurship.

Since establishing new grounds for social legitimacy is challenging and often only possible when a group of established organizations and institutions actively apply pressure on the moral order (SUCHMANN, 1995), potential entrepreneurs are seldom able to influence and change their own socio-cultural environments. Thus, creating a regional culture where entrepreneurial activity enjoys a high level of social legitimacy, and which is optimally adjusted to the socio-economic characteristics of the region, requires collective (policy) action by different institutional and organizational actors. Promotional measures aiming to facilitate 
social legitimacy should aspire to establish a common awareness of the economic and social benefits of entrepreneurship among the individuals living in the region and the regional economy as a whole. Entrepreneurship policies should also not neglect the potential of the likes of social and sports clubs or cultural events to act as catalysts for institutionalized social interaction at the local level (FINK et al., 2012). Such events and venues stimulate social interaction, and may thus serve as vehicles for the transmission of information that can help to establish regional social legitimacy of entrepreneurship. 
Variable (all measured on a 6-point Likert-style scale)

CFA CFA

Wave 1 Wave 2

Intention

('How well do the following statements describe you?')

I plan to take steps to start a business in the next 12 months

.89

.90

I intend to take steps to start a business in the next 12 months

.93

I will try to take steps to start a business in the next 12 months

.94

\section{Behaviour}

('Please assess:')

How much effort have you applied to activities aimed at starting a business in the last 12

months?

How much time have you spent on activities aimed at starting a business in the last 12

months?

How much money have you invested in activities aimed at starting a business in the last

12 months?

\section{Attitude}

('Please rate the following statement based on the word pairs provided: "For me, taking steps to start a business in the next 12 months would be..."')

...unpleasant - attractive

...useless - useful

...foolish - wise 


\section{Subjective norm}

The subjective norm items have been computed by multiplying the following attitude items ('How well do the following statements describe your situation?') with their respective motivation-to-comply items ('And how much do you care about what these people think, if you want to take steps to start a business in the next 12 months?')

My closest family members think that I should take steps to start a business in the next 12 months

My best friends think that I should take steps to start a business in the next 12 months

\section{Perceived behavioural control}

('Please indicate your opinion to the following statements.')

If I wanted to, I could take steps to start a business in the next 12 months

If I took steps to start a business in the next 12 months, I would be able to control the

If I wanted to take steps to start a business in the next 12 months, no external factor, independent of myself, would hinder me in taking such action

\section{Regional social legitimacy of entrepreneurship}

('How well do the following statements describe your current place of residence?')

NB: In the German and Finnish questionnaires, the words used for place of residence refer unambiguously to the city, town or municipality where the person lives (German:

'Wohnort'; Finnish: 'asuinkunta').

Pragmatic legitimacy 
life

The values and beliefs of entrepreneurs in my municipality are similar to my own

\section{Moral legitimacy}

Entrepreneurs in my place of residence contribute to the well-being of local people

Local entrepreneurs operate according to the commonly accepted norms in my place of

residence

The activity of the entrepreneurs in my place of residence supports the local economy

\section{Cognitive legitimacy}

The activity of entrepreneurs in my place of residence is necessary

Notes: The CFA column reports the standardised loading of the item on the respective factor in the confirmatory factor analysis for the first wave $(N=2025)$ and the second wave $(N=984)$ data 


\section{REFERENCES}

AJZEN I. (1991) The theory of planned behaviour, Organizational Behaviour and Human Decision Processes 50, 179-211.

AJZEN I. (2011) Constructing a theory of planned behavior questionnaire. http://people.umass.edu/aizen/tpb.diag.html (18 March 2011).

ALDRICH H. E. and FIOL C. M. (1994) Fools rush in? The institutional context of industry creation, Academy of Management Review 19, 645-670.

ANDERSON J. C. and GERBING, D. W. (1988) Structural equation modeling in practice: A review and recommended two-step approach, Psychological Bulletin 103, 411-423.

ANDERSON M. and KOSTER S. (2011) Sources of persistence in regional start-up rates Evidence from Sweden, Journal of Economic Geography 11, 179-201.

ANGRIST J. A. and PISCHKE, J.-S. (2009) Mostly Harmless Econometrics: An Empiricist's Companion. Princeton University Press, Princeton and Oxford.

AOYAMA Y. (2009) Entrepreneurship and regional Culture: The case of Hamamatsu and Kyoto, Japan, Regional Studies 43, 495-512.

ARMINGTON C. and ACS Z. J. (2002) The determinants of regional variation in new firm formation, Regional Studies 36, 33-45.

ARMITAGE C. J. and CONNER M. (2001) Efficacy of the theory of planned behaviour: A metaanalytic review, British Journal of Social Psychology 40, 471-499.

ASHCROFT B., LOVE J. H. and MALLOY E. (1991) New firm formation in the British counties with special reference to Scotland, Regional Studies 25, 395-409.

AUDRETSCH D. B. and FRITSCH, M. (1994). The geography of firm births in Germany, Regional Studies 28, 359-365.

AUDRETSCH D. B. and KEILBACH M. (2004) Entrepreneurship capital and economic performance, Regional Studies 38, 949-959. 
BITEKTINE A. (2011) Towards a theory of social judgments of organizations: The case of legitimacy, reputation, and status, Academy of Management Review 36, 151-179.

BOSMA N. STEL A. and SUDDLE K. (2008) The geography of new firm formation: Evidence from independent start-ups and new subsidiaries in the Netherlands, International Entrepreneurship and Management Journal 4, 129-146.

BOSMA N. and SCHUTJENS V. (2011) Understanding regional variation in entrepreneurial activity and entrepreneurial attitude in Europe, Annals of Regional Science 47, 711-742.

BRAMBOR T., CLARK W. R. and GOLDER M. (2006) Understanding interaction models: Improving empirical analyses, Political Analysis 14, 63-82.

BRIXY U. and Grotz R. (2007) Regional patterns and determinants of birth and survival of new firms in Western Germany, Entrepreneurship \& Regional Development 19, 293-312.

CONNER M. and ARMITAGE C. J. (1998) Extending the theory of planned behavior: A review and avenues for further research, Journal of Applied Social Psychology 28, 1429-1464.

DAVIDSSON P. and WIKLUND J. (1997) Values, beliefs and regional variations in new firm formation rates, Journal of Economic Psychology 18, 179-99.

DEEPHOUSE D. L. and SUCHMANN M. C. (2008) Legitimacy in organizational institutionalism, in GREENWOOD R., OLIVER C., SAHLIN K. and SUDDABY R. (Eds), The SAGE Handbook of Organizational Institutionalism, pp. 49-77. Sage: Thousand Oaks CA.

DIMAGGIO P. and POWELL W. W. (1983) The iron cage revisited: Institutional isomorphism and collective rationality in organizational fields, American Sociological Review 48, 147-160.

ETZIONI A. (1987) Entrepreneurship, adaptation and legitimation, Journal of Economic Behavior and Organization 8, 175-189.

FINK M., LOIDL S. and LANG R. (2012) Community Based Entrepreneurship and Rural Development. Routledge: London. 
FORNAHL D. (2003) Entrepreneurial activities in a regional context, in FORNAHL D. and BRENNER T. (Eds), Cooperation, Networks, and Institutions in Regional Innovation Systems, pp. 38-57. Cheltenham: Edward Elgar.

FRITSCH M. and MUELLER P. (2004) Effects of new business formation on regional development over time, Regional Studies 38, 961-975.

FRITSCH M. and SCHMUDE J. ( 2006) Entrepreneurship in the Region. Springer: New York.

FRITSCH M. and FALCK O. (2007) New business formation by industry over space and time: A multidimensional analysis, Regional Studies, 41, 157-172.

FRITSCH M. and MUELLER P. (2007) The persistence of regional new business formationactivity over time - assessing the potential of policy promotion programs, Journal of Evolutionary Economics 17, 299-315.

FRITSCH M. and WYRWICH M. (in this issue) The long persistence of regional levels of entrepreneurship: Germany 1925 to 2005 , Regional Studies.

GERTLER M. (2010) Rules of the game: The place of institutions in regional economic change, Regional Studies 44, 1-15.

GIDDENS A. (1984) The Constitution of Society. University of California Press: Berkeley.

GONZÁLEZ S. and HEALEY P. (2005) A Sociological institutionalist approach to the study of innovation in governance capacity, Urban Studies 42, 2055-2069.

GREENWOOD R., RAYNARD M., KODEIH F., MICELOTTA E. R. and LOUNSBURY M. (2011) Institutional Complexity and Organizational Responses, The Academy of Management Annals 5, 317-371.

HAYTER R. (2004) Economic geography as dissenting institutionalism: The embeddedness, evolution and differentiation of regions, Geografiska Annaler B 86, 95-115.

HODGSON G. M. (2006) What are institutions? Journal of Economic Issues 40, 1-25. 
HOLMÉN H. (1995) What's new and what's regional in the "new regional geography"? Geografiska Annaler 77 B, 47-63.

HOX, J. J. (2010) Multilevel Analysis: Techniques and Applications. Routledge: New York.

HU L. and BENTLER P. M. (1999) Cutoff criteria for fit indexes in covariance structure analysis: Conventional criteria versus new alternatives, Structural Equation Modeling: A Multidisciplinary Journal 6, 1-55.

KAUTONEN T., VAN GELDEREN M. and TORNIKOSKI E. T. (2013) Predicting entrepreneurial behaviour: A test of the theory of planned behaviour, Applied Economics 45, 697-707.

KAUTONEN T., VAN GELDEREN M. and FINK M. (2015). Robustness of the theory of planned behaviour in predicting entrepreneurial intentions and actions, Entrepreneurship Theory \& Practice 39, DOI: 10.1111/etap.12056.

KEEBLE D. and WALKER S. (1994) New firms, small firms and dead firms: Spatial patterns and determinants in the United Kingdom, Regional Studies 28, 411-427.

KIBLER E. (2013) The formation of entrepreneurial intentions in a regional context, Entrepreneurship \& Regional Development: An International Journal 25, 293-323.

KOLVEREID L. (1996) Prediction of employment status choice intentions, Entrepreneurship Theory \& Practice 21, 47-57.

LAFUENTE E., VAILLANT Y. and RIALP J. (2007) Regional differences in the influence of role models: Comparing the entrepreneurial process of rural Catalonia, Regional Studies 41, 779795.

LANG R. and ROESSL D. (2011) Contextualizing the governance of community co-operatives: Evidence from Austria and Germany, Voluntas 22, 706-730.

LANG R., FINK M. and KIBLER, E. (2013) Understanding place-based entrepreneurship in rural Central Europe: A comparative institutional analysis, International Journal of Small Business, DOI: $10.1177 / 0266242613488614$. 
LEE S. Y., FLORIDA R. and ACS Z. J. (2004). Creativity and entrepreneurship: A regional analysis of new firm formation, Regional Studies 38, 879-891.

LÉVESQUE M. and MINNITI M. (2006) The effect of aging on entrepreneurial behavior, Journal of Business Venturing 21, 177-194.

LIAO J. and WELSCH H. (2005) Roles of social capital in venture creation: Key dimensions and research implications, Journal of Small Business Management 43, 345-362.

LIÑÁN F., URBANO D. and GUERRERO M. (2011) Regional variations in entrepreneurial cognitions: Start-up intentions of university students in Spain, Entrepreneurship \& Regional Development 23, 187-215.

MARQUIS C. and BATTILANA J. (2009) Acting globally but thinking locally? The enduring influence of local communities on organizations, Research in Organizational Behavior 29, $283-$ 302.

MARTIN R. (2000) Institutional approaches in economic geography, in SHEPPARD E. and BARNES T. J. (Eds) A Companion to Economic Geography, pp. 77-94. Blackwell Publishing: Oxford.

MINNITI M. (2005) Entrepreneurship and network externalities, Journal of Economic Behavior \& Organization 57, 1-27.

MUELLER P., VAN STEL A. J. and STOREY D. J. (2008) The effects of new firm formation on regional development over time: The case of Great Britain, Small Business Economics 30, 5971.

NORTH D. C. (1990) Institutions, institutional change and economic performance. Cambridge University Press: Cambridge.

OECD (2006) The new rural paradigm: Policy and governance. Working Paper on Territorial Policy in Rural Areas. Paris: OECD. 
OSTROM E. (2005) Doing institutional analysis: Digging deeper than markets and hierarchies, in MÉNARD C. and SHIRLEY M. (Eds) Handbook of New Institutional Economics, pp. 819-848. Springer: Dordrecht.

PARKER S. C. (2009) The Economics of Entrepreneurship. Cambridge: Cambridge University Press.

RAFIQUI P. S. (2009) Evolving economic landscapes: Why new institutional economics matters for economic geography, Journal of Economic Geography 9, 329-353.

REYNOLDS P. D., STOREY D. J. and WESTHEAD P. (1994). Cross-national comparisons of the variation in new firm formation rates, Regional Studies 28, 443-456.

REYNOLDS P. D. (1997) Who starts new firms? Preliminary explorations of firms-in-gestation, Small Business Economics 5, 449-462.

RODRIQUEZ-POSE, A. (2013) Do institutions matter for regional development? Regional Studies 47, 1034-1047.

ROGELBERG S. G. and STANTON J. M. (2007) Understanding and dealing with organizational survey nonresponse, Organizational Research Methods 10, 195-209.

SCOTT W. R. (1995) Institutions and Organizations. Sage: Thousand Oaks.

SCOTT W. R. (2010) Reflections: The past and future of research on institutions and institutional change, Journal of Change Management 10, 5-21.

SHEERAN P. (2002) Intention-behaviour relations: A conceptual and empirical overview, European Review of Social Psychology 12, 1-36.

SOUITARIS V., ZERBINATI S. and AL-LAHAM A. (2007) Do entrepreneurship programmes raise entrepreneurial intention of science and engineering students? The effect of learning, inspiration and resources, Journal of Business Venturing 22, 566-591.

STAM E. (2010) Entrepreneurship, evolution and geography, in BOSCHMA R. and Martin R. L. (Eds) The Handbook of Evolutionary Economic Geography, pp. 307-348. Edward Elgar: Cheltenham. 
STATISTICS AUSTRIA (2011a) Statistical classifications of regions: http://www.statistik.at/web_en/classifications/regional_breakdown/index.html (June 2011).

STATISTICS AUSTRIA (2011b) Population by demographic characteristics: http://www.statistik.at/web_de/statistiken/bevoelkerung/bevoelkerungsstruktur/bevoelkerung_n ach_alter_geschlecht/index.html (June 2011).

STATISTICS AUSTRIA (2013) Regional Statistical Database - StatCube Service. http://www.statistik.at/web_en/publications_services/superstar_database/index.html (March 2013)

STATISTICS FINLAND (2011) Statistical grouping of regions: http://www.stat.fi/meta/luokitukset/kuntaryhmitys/001-2011/index_en.html (June 2011)

STATISTICS FINLAND (2013) Regional Statistical Database - StatFin Service. http://pxweb2.stat.fi/database/StatFin/databasetree_en.asp (February 2013)

STERNBERG R. (2009) Regional dimensions of entrepreneurship, Foundations and Trends in Entrepreneurship 5, 211-340.

SUCHMANN M. C. (1995) Managing legitimacy: Strategic and institutional approaches, Academy of Management Review 20, 571-611.

THORNTON P. H. and FLYNN K. H. (2003) Entrepreneurship, networks, and geographies, in ACS Z. J. and AUDRETSCH D. B. (Eds) Handbook of Entrepreneurship Research, pp. 401433. Kluwer: New York.

TRETTIN L. and WELTER F. (2011) Challenges for spatially oriented entrepreneurship research, Entrepreneurship \& Regional Development 23, 575-602.

TÖDTLING F. and WANZENBÖCK H. (2003) Regional differences in structural characteristics of start-ups, Entrepreneurship \& Regional Development, 15, 351-370. 
VAILLANT Y. and LAFUENTE E. (2007) Do different institutional frameworks condition the influence of local fear of failure and entrepreneurial examples over entrepreneurial activity? Entrepreneurship \& Regional Development 19, 313-337.

VAN STEL A. J. and STOREY D. J. (2004) The link between firm births and job creation: Is there a upas tree effect? Regional Studies 38, 893-910.

WELTER F. (2011) Conceptual challenges and ways forward. Entrepreneurship Theory \& Practice, $35,165-184$.

XAVIER S. R., KELLEY D., KEW J., HERRINGTON M. and VORDERWÜLBECKE A. (2013) Global Entrepreneurship Monitor, 2012 - Global Report. Babson Park, MA, U.S.: Babson College; Santiago, Chile: Universidad del Desarrollo; Kuala Lumpur, Malaysia: Universiti Tun Abdul Razak; London, U.K.: Global Entrepreneurship Research Association. 
Table 1. Regional socio-economic characteristics

\begin{tabular}{llcc}
\hline Variable & Description & Mean & SD \\
\hline Population density & $\begin{array}{l}\text { Number of inhabitants per km }{ }^{2} \text { (2011); log transformed for } \\
\text { regression analysis }\end{array}$ & 479.9 & 873.7 \\
Educational level & $\begin{array}{l}\text { Proportion of people (\%) aged 25-64 years with a tertiary education } \\
\text { degree (level 5 or 6 in the ISCED classification, 2010) }\end{array}$ & .14 \\
Age structure & $\begin{array}{l}\text { Proportion of people (\%) aged 25-44 years in the population aged } \\
\text { between 20 and 64 years (2011) }\end{array}$ & .42 & .07 \\
Service sector & $\begin{array}{l}\text { Proportion of labour force (in \%) employed in the service sector } \\
\text { employment }\end{array}$ & .70 & .13 \\
Unemployment rate & $\begin{array}{l}\text { Number of unemployed individuals divided by the number of } \\
\text { individuals in the labour force (2011) }\end{array}$ & .08 & .03 \\
Entry rate & $\begin{array}{l}\text { Number of business start-ups in the period 2005-2010, divided by } \\
\text { the stock of firms } \\
\text { Gross regional product (in euro per capita) (2010); log transformed }\end{array}$ & .08 & .02 \\
GRP & $\begin{array}{l}\text { for regression analysis } \\
\text { Growth of GRP, 2005-2010 (in \%) }\end{array}$ & 78047 \\
GRP growth & & .13 \\
\hline
\end{tabular}

Note: Means and SDs across the 65 regions in the sample. 
Table 2. Descriptive statistics for the survey data

\begin{tabular}{|c|c|c|c|c|c|c|c|c|c|}
\hline & \multicolumn{2}{|c|}{ Range } & \multicolumn{2}{|c|}{$\begin{array}{l}\text { (1) First wave } \\
\text { (all, } N=2025 \text { ) }\end{array}$} & \multicolumn{2}{|c|}{$\begin{array}{c}\text { (2) First wave } \\
\text { (not in second wave, } \\
N=1041 \text { ) }\end{array}$} & \multicolumn{2}{|c|}{$\begin{array}{l}\text { (3) Second wave } \\
(N=984)\end{array}$} & \multirow{2}{*}{$\begin{array}{c}\text { Difference } \\
\text { (2) and (3) }\end{array}$} \\
\hline & Min & $\operatorname{Max}$ & Mean & SD & Mean & SD & Mean & SD & \\
\hline Behaviour & 1 & 5.67 & & & & & 1.23 & .63 & \\
\hline Intention & 1 & 6 & 1.67 & 1.14 & 1.64 & 1.10 & 1.70 & 1.18 & $t=1.23$ \\
\hline Attitude & 1 & 6 & 2.74 & 1.29 & 2.72 & 1.26 & 2.77 & 1.32 & $t=.82$ \\
\hline Subjective norm & 1 & 24 & 4.52 & 3.75 & 4.47 & 3.71 & 4.56 & 3.79 & $t=.54$ \\
\hline PBC & 1 & 6 & 3.19 & 1.31 & 3.15 & 1.30 & 3.23 & 1.32 & $t=1.26$ \\
\hline Regional social legitimacy & 1 & 6 & 4.65 & .77 & 4.59 & .80 & 4.72 & .73 & $t=3.92 * *$ \\
\hline Acceptance of failure & 1 & 6 & 3.82 & 1.05 & 3.78 & 1.08 & 3.85 & 1.02 & $t=1.37$ \\
\hline Age & 20 & 64 & 43.68 & 12.65 & 43.12 & 12.85 & 44.27 & 12.40 & $t=2.05^{*}$ \\
\hline Female & 0 & 1 & .58 & & .56 & & .60 & & $\chi_{\text {ldf }=3.78}^{2}$ \\
\hline Entrepreneurial experience & 0 & 1 & .14 & & .14 & & .14 & & $\chi_{1 \mathrm{df}=.01}^{2}$ \\
\hline Education & & & & & & & & & $\chi_{3 \mathrm{df}=}^{2}=6.75$ \\
\hline Primary & 0 & 0 & .08 & & .09 & & .06 & & \\
\hline Vocational & 0 & 1 & .22 & & .23 & & .21 & & \\
\hline Secondary & 0 & 1 & .33 & & .32 & & .34 & & \\
\hline Tertiary & 0 & 1 & .37 & & .36 & & .38 & & \\
\hline Occupational status & & & & & & & & & $\chi_{3 \mathrm{df}=2.10}^{2}$ \\
\hline Employed & 0 & 0 & .71 & & .70 & & .72 & & \\
\hline Job seeker & 0 & 1 & .06 & & .06 & & .05 & & \\
\hline Retired / incapacity & 0 & 1 & .10 & & .10 & & .10 & & \\
\hline Other not in labour force & 0 & 1 & .13 & & .14 & & .13 & & \\
\hline Austria & 0 & 1 & .22 & & .20 & & .26 & & $\chi_{1 \mathrm{df}=10.84 * *}^{2}$ \\
\hline Region type $^{1}$ & & & & & & & & & $\chi_{2 \mathrm{df}=.40}^{2}$ \\
\hline Rural & 0 & 1 & $.16 / .31$ & & .15 & & .16 & & \\
\hline Semi-urban & 0 & 1 & $.22 / .32$ & & .23 & & .22 & & \\
\hline Urban & 0 & 0 & $.62 / .37$ & & .62 & & .62 & & \\
\hline
\end{tabular}

Notes: The difference column displays the $t$-statistic (2023 df) for continuous and the chi-squared statistic for indicator variables, $* p<0.05, * *$ $p<0.01$ (two-tailed t-test). ${ }^{1}$ Column (1) presents the percentages of observations and regions: e.g. $16 \%$ of respondents live in rural regions while $31 \%$ of the included regions are classified as rural. 
Table 3. Correlations for the survey data

\begin{tabular}{|c|c|c|c|c|c|c|c|c|c|c|}
\hline & 1. & 2. & 3. & 4. & 5. & 6. & 7. & 8. & 9. & 10. \\
\hline 1. Behaviour & 1 & & & & & & & & & \\
\hline 2. Intention & $.57^{*}$ & 1 & & & & & & & & \\
\hline 3. Attitude & $.42 *$ & $.62 *$ & 1 & & & & & & & \\
\hline 4. Subjective norm & $.41^{*}$ & $.61^{*}$ & $.57 *$ & 1 & & & & & & \\
\hline 5. $\mathrm{PBC}$ & $.31 *$ & $.39 *$ & $.41^{*}$ & $.29 *$ & 1 & & & & & \\
\hline 6. Regional social legitimacy & .04 & $.07 *$ & $.12 *$ & $.10^{*}$ & $.10^{*}$ & 1 & & & & \\
\hline 7. Age & -.05 & -.04 & $-.09 *$ & $-.07 *$ & .02 & $.07 *$ & 1 & & & \\
\hline 8. Acceptance of failure & -.04 & -.04 & -.00 & -.02 & .03 & $.27 *$ & .01 & 1 & & \\
\hline 9. Entrepreneurial experience & $.15^{*}$ & $.19 *$ & $.15^{*}$ & $.14^{*}$ & $.21 *$ & .02 & $.19 *$ & -.01 & 1 & \\
\hline 10. Female & -.05 & $-.14 *$ & $-.14 *$ & $-.08 *$ & $-.17 *$ & .04 & $-.07 *$ & $.07 *$ & $-.07 *$ & 1 \\
\hline 11. Austria & -.02 & -.02 & $-.09 *$ & $-.10^{*}$ & .03 & $-.08 *$ & $-.08 *$ & -.02 & -.03 & $-.07 *$ \\
\hline
\end{tabular}

Notes: Pearson correlations. All correlations are based on the full first-wave sample $(N=2025)$ except for column 1 which is based on the second-wave sample $(N=984)$ * denotes significance at the $5 \%$ level. 
Table 4. Random-intercept regression estimates of the unconditional effects

\begin{tabular}{|c|c|c|c|c|}
\hline & \multicolumn{2}{|c|}{$\begin{array}{l}\text { Dependent variable: } \\
\text { intention }\end{array}$} & \multicolumn{2}{|c|}{$\begin{array}{c}\text { Dependent variable: } \\
\text { behaviour }\end{array}$} \\
\hline & $\beta$ & SE & $\beta$ & SE \\
\hline \multicolumn{5}{|l|}{ Individual level } \\
\hline Intention & & & $.28 * *$ & .02 \\
\hline Regional social legitimacy & -.01 & .02 & -.00 & .02 \\
\hline Attitude & $.32 * *$ & .02 & & \\
\hline Subjective norm & $.11^{* *}$ & .01 & & \\
\hline $\mathrm{PBC}$ & $.10^{* *}$ & .02 & $.05 * *$ & .01 \\
\hline Age & $.03 *$ & .01 & -.00 & .01 \\
\hline Age squared & $-.00 *$ & .00 & .00 & .00 \\
\hline Female & $-.08^{*}$ & .04 & .06 & .03 \\
\hline Entrepreneurial experience & $.19^{* *}$ & .05 & .09 & .05 \\
\hline Acceptance of failure & -.03 & .02 & -.02 & .02 \\
\hline \multicolumn{5}{|l|}{ Education } \\
\hline vocational & .03 & .08 & -.03 & .08 \\
\hline secondary & .05 & .08 & -.04 & .07 \\
\hline tertiary & .04 & .08 & -.03 & .08 \\
\hline \multicolumn{5}{|l|}{ Occupational status } \\
\hline job seeker & .10 & .08 & .04 & .07 \\
\hline retired & .08 & .07 & -.04 & .06 \\
\hline other & $.13^{*}$ & .06 & .02 & .06 \\
\hline \multicolumn{5}{|l|}{ Regional level } \\
\hline Austria & .18 & .14 & .13 & .13 \\
\hline \multicolumn{5}{|l|}{ Region type } \\
\hline rural & -.07 & .09 & .05 & .08 \\
\hline semi-urban & -.10 & .07 & .06 & .07 \\
\hline Population density (log) & .00 & .02 & .01 & .02 \\
\hline Entry rate & .02 & .04 & -.03 & .03 \\
\hline Educational level & -.02 & .62 & -.41 & .56 \\
\hline Unemployment rate & -1.05 & 1.07 & -1.26 & .97 \\
\hline GRP $(\log )$ & $-.31 *$ & .15 & .08 & .14 \\
\hline Growth of GRP & -.09 & .29 & -.12 & .27 \\
\hline Age structure & .19 & .56 & -.25 & .53 \\
\hline Service sector employment & .06 & .28 & .08 & .26 \\
\hline Intercept & 2.56 & 1.53 & .52 & 1.44 \\
\hline Observations & \multicolumn{2}{|c|}{2025} & \multicolumn{2}{|c|}{984} \\
\hline Overall $\mathrm{R}^{2}$ & \multicolumn{2}{|c|}{.30} & \multicolumn{2}{|c|}{.19} \\
\hline Log likelihood & \multicolumn{2}{|c|}{-2417.94} & \multicolumn{2}{|c|}{-729.49} \\
\hline
\end{tabular}

Notes: Maximum likelihood estimates. Random-intercept variances in all models are negligibly small and not significant, and thus not reported. * and ** denote statistical significance at the $5 \%$ and $1 \%$ levels (two-tailed), respectively. Overall $\mathrm{R}^{2}$ is computed as the residual variance of the focal model subtracted from the residual variance of the null model (without predictors) and then divided by the residual variance of the null model. 
Table 5. Marginal effects of attitude, subjective norms, PBC and intention at different levels of regional social legitimacy of entrepreneurship

\begin{tabular}{llllll}
\hline & & \multicolumn{3}{c}{ Dependent variable: intention } & \multicolumn{2}{c}{ Dependent variable: behaviour } \\
& Attitude & Subjective norms & PBC & Intention & PBC \\
\hline Social legitimacy -2 SD & $.27 * *(.03)$ & $.10^{* *}(.01)$ & $.09 * *(.03)$ & $.23 * *(.04)$ & $.12 * *(.03)$ \\
Social legitimacy -1 SD & $.30^{* *}(.02)$ & $.11^{* *}(.01)$ & $.09 * *(.02)$ & $.25 * *(.03)$ & $.08^{* *}(.02)$ \\
Social legitimacy +1 SD & $.34^{* *}(.02)$ & $.11^{* *}(.01)$ & $.10^{* *}(.02)$ & $.29 * *(.02)$ & $.02(.02)$ \\
Social legitimacy +2 SD & $.36^{* *}(.04)$ & $.11^{* *}(.01)$ & $.11^{* *}(.03)$ & $.31^{* *}(.03)$ & $-.01(.03)$ \\
\hline
\end{tabular}

Notes: Maximum likelihood estimates of coefficients and standard errors. * and ** denote statistical significance at the $5 \%$ and $1 \%$ levels (two-tailed), respectively. In addition to the multiplicative interaction terms, each model estimate contains the full set of covariates in the respective models in Table 4 . 
Table 6. Marginal effects of attitude, subjective norms, PBC and intention at different levels of regional social legitimacy and socio-economic

\section{characteristics}

\begin{tabular}{|c|c|c|c|c|c|c|c|c|c|c|}
\hline \multirow[b]{3}{*}{ Social legitimacy } & \multicolumn{6}{|c|}{ Dependent variable: intention } & \multicolumn{4}{|c|}{ Dependent variable: behaviour } \\
\hline & \multicolumn{2}{|c|}{ Attitude } & \multicolumn{2}{|c|}{ Subjective norms } & \multicolumn{2}{|c|}{$\mathrm{PBC}$} & \multicolumn{2}{|c|}{ Intention } & \multicolumn{2}{|c|}{ PBC } \\
\hline & $-1 \mathrm{SD}$ & $+1 \mathrm{SD}$ & $-1 \mathrm{SD}$ & $+1 \mathrm{SD}$ & $-1 \mathrm{SD}$ & $+1 \mathrm{SD}$ & $-1 \mathrm{SD}$ & $+1 \mathrm{SD}$ & $-1 \mathrm{SD}$ & $+1 \mathrm{SD}$ \\
\hline \multicolumn{11}{|l|}{ Population density } \\
\hline$-1 \mathrm{SD}$ & $.27 * *$ & $.35^{* *}$ & $.09 * *$ & $.11 * *$ & $.11^{* *}$ & $.15^{* *}$ & $.27 * *$ & $.27 * *$ & $.09 * *$ & .01 \\
\hline$+1 \mathrm{SD}$ & $.31 * *$ & $.33 * *$ & $.12 * *$ & $.12 * *$ & $.06^{*}$ & $.08^{* *}$ & $.28 * *$ & $.29 * *$ & $.06^{*}$ & .04 \\
\hline \multicolumn{11}{|l|}{ Entry rate } \\
\hline$-1 \mathrm{SD}$ & $.30 * *$ & $.35^{* *}$ & $.12 * *$ & $.13 * *$ & $.06^{*}$ & $.07^{*}$ & $.30 * *$ & $.25 * *$ & $.09 * *$ & .03 \\
\hline$+1 \mathrm{SD}$ & $.28 * *$ & $.35^{* *}$ & $.08 * *$ & $.11^{* *}$ & $.12 * *$ & $.16^{* *}$ & $.24 * *$ & $.32 * *$ & $.06^{*}$ & .01 \\
\hline \multicolumn{11}{|l|}{ Educational level } \\
\hline$-1 \mathrm{SD}$ & $.29 * *$ & $.35^{* *}$ & $.10^{* *}$ & $.11^{* *}$ & $.08 * *$ & $.14 * *$ & $.29 * *$ & $.28 * *$ & $.08^{* *}$ & -.00 \\
\hline +1 SD & $.28 * *$ & $.34 * *$ & $.11 * *$ & $.12 * *$ & $.09 * *$ & $.08 * *$ & $.26^{* *}$ & $.28 * *$ & $.07 * *$ & $.04 *$ \\
\hline \multicolumn{11}{|l|}{ Unemployment rate } \\
\hline$-1 \mathrm{SD}$ & $.30 * *$ & $.37 * *$ & $.11^{* *}$ & $.13 * *$ & $.06^{*}$ & $.12 * *$ & $.39 * *$ & $.32 * *$ & $.13 * *$ & .02 \\
\hline$+1 \mathrm{SD}$ & $.29 * *$ & $.31 * *$ & $.09 * *$ & $.10 * *$ & $.11^{* *}$ & $.10 * *$ & $.15^{* *}$ & $.22 * *$ & -.01 & .02 \\
\hline \multicolumn{11}{|l|}{ GRP } \\
\hline$-1 \mathrm{SD}$ & $.29 * *$ & $.36^{* *}$ & $.10^{* *}$ & $.12 * *$ & $.10^{* *}$ & $.14 * *$ & $.24 * *$ & $.29 * *$ & $.10 * *$ & .02 \\
\hline$+1 \mathrm{SD}$ & $.29 * *$ & $.33 * *$ & $.11^{* *}$ & $.11 * *$ & $.07 *$ & $.08 * *$ & $.31 * *$ & $.27 * *$ & .04 & .03 \\
\hline \multicolumn{11}{|l|}{ Growth of GRP } \\
\hline$-1 \mathrm{SD}$ & $.30 *$ & $.32 * *$ & $.10 * *$ & $.10 * *$ & $.08 * *$ & $.08 * *$ & $.21 * *$ & $.32 * *$ & $.08 * *$ & $.05 *$ \\
\hline$+1 \mathrm{SD}$ & $.28 * *$ & $.37 * *$ & $.10 * *$ & $.13 * *$ & $.09 * *$ & $.15^{* *}$ & $.34 * *$ & $.25^{* *}$ & $.08 * *$ & -.00 \\
\hline \multicolumn{11}{|l|}{ Age structure } \\
\hline$-1 \mathrm{SD}$ & $.29 * *$ & $.32 * *$ & $.09 * *$ & $.11 * *$ & $.10 * *$ & $.13 * *$ & $.22 * *$ & $.26^{* *}$ & $.10 * *$ & .03 \\
\hline$+1 \mathrm{SD}$ & $.29 * *$ & $.37 * *$ & $.11^{* *}$ & $.12 * *$ & $.07 * *$ & $.09 * *$ & $.33 * *$ & $.29 * *$ & $.06^{*}$ & .02 \\
\hline \multicolumn{11}{|c|}{ Service sector employment } \\
\hline$-1 \mathrm{SD}$ & $.30 * *$ & $.36^{* *}$ & $.10^{* *}$ & $.11^{* *}$ & $.10 * *$ & $.15^{* *}$ & $.29 * *$ & $.30 * *$ & $.09 * *$ & .02 \\
\hline
\end{tabular}




\section{Table 7. Summary of the main findings}

Unconditional effect Conditional on regional social legitimacy Conditional on regional sor socio-economic characteris

Attitude has a positive effect on intention

Subjective norms have a positive effect on intention

$\mathrm{PBC}$ has a positive effect on intention

Intention has a positive effect on behaviour

PBC has a positive impact on behaviour
Attitude has a stronger effect when regional Not affected by socio-econ social legitimacy is high characteristics of the regior

The effect of subjective norms is not conditional on regional social legitimacy

Not affected by socio-econ characteristics of the regior

The effect of $\mathrm{PBC}$ is conditional on regional $\mathrm{PBC}$ has a stronger effect social legitimacy only in certain regional contexts regional social legitimacy

...population density is lor ...entry rate is high ...education level is low ...unemployment rate is lo ...GRP is low ...service sector employmı

The effect of intention is stronger when regional social legitimacy is high; however the effect varies notably when socioeconomic features of the region are accounted for

The effect of intention is st regional social legitimacy i ...entry rate is high

...unemployment rate is hi ...GRP or its growth is low ...proportion of people age The effect of intention is $\mathrm{w}$ regional social legitimacy $i$

...entry rate is low

...unemployment rate is lo

...GRP or its growth is hig

...proportion of people age

$\mathrm{PBC}$ has a stronger effect when regional social legitimacy is low; there is minor variation in the effect when the socioeconomic features of the region are accounted for
The effect of PBC is non-s level of regional social legi ...unemployment rate is hi: ...GRP is high ...service sector employme 
Figure 1. Research model

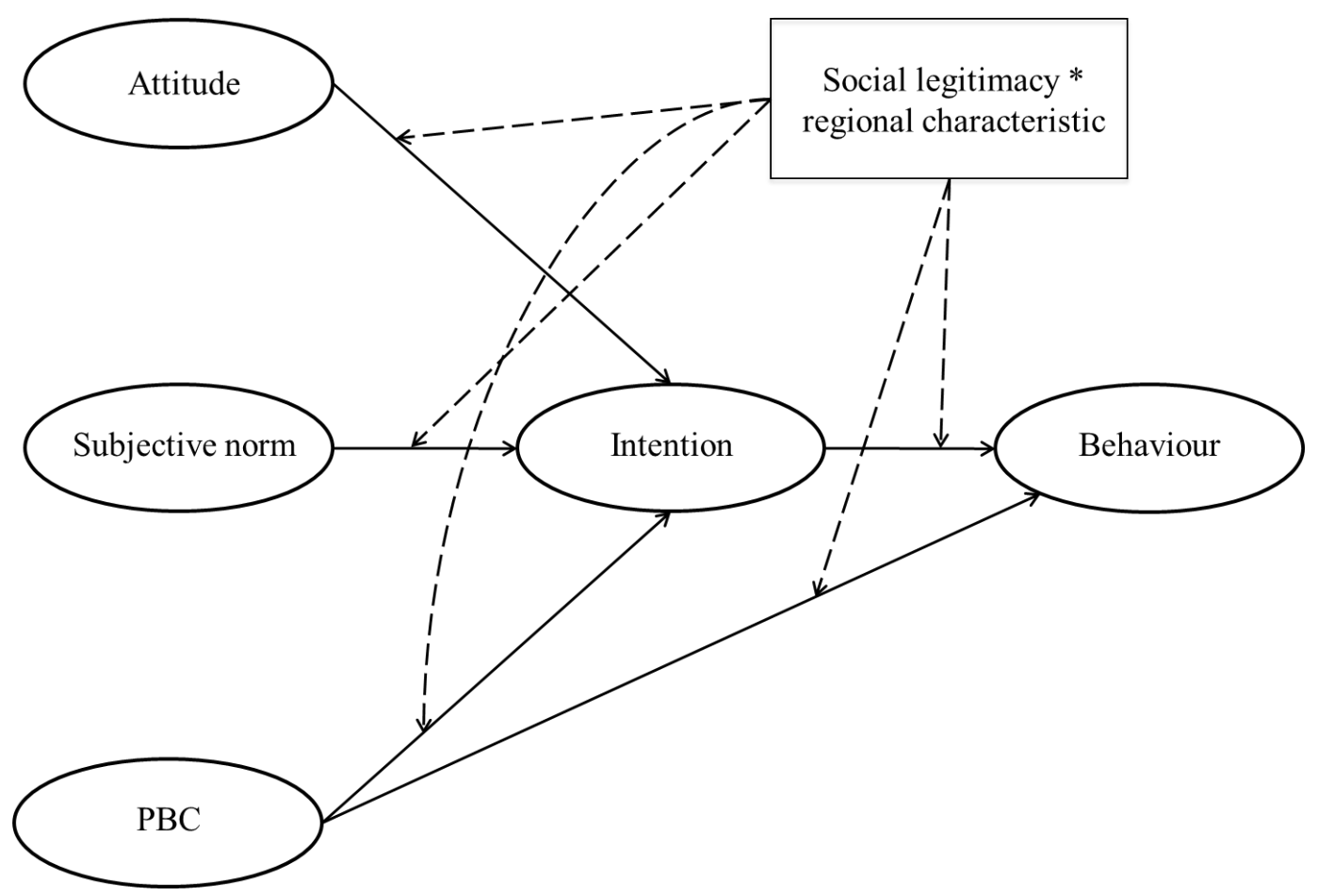


Figure 2. Austrian regions in the sample.

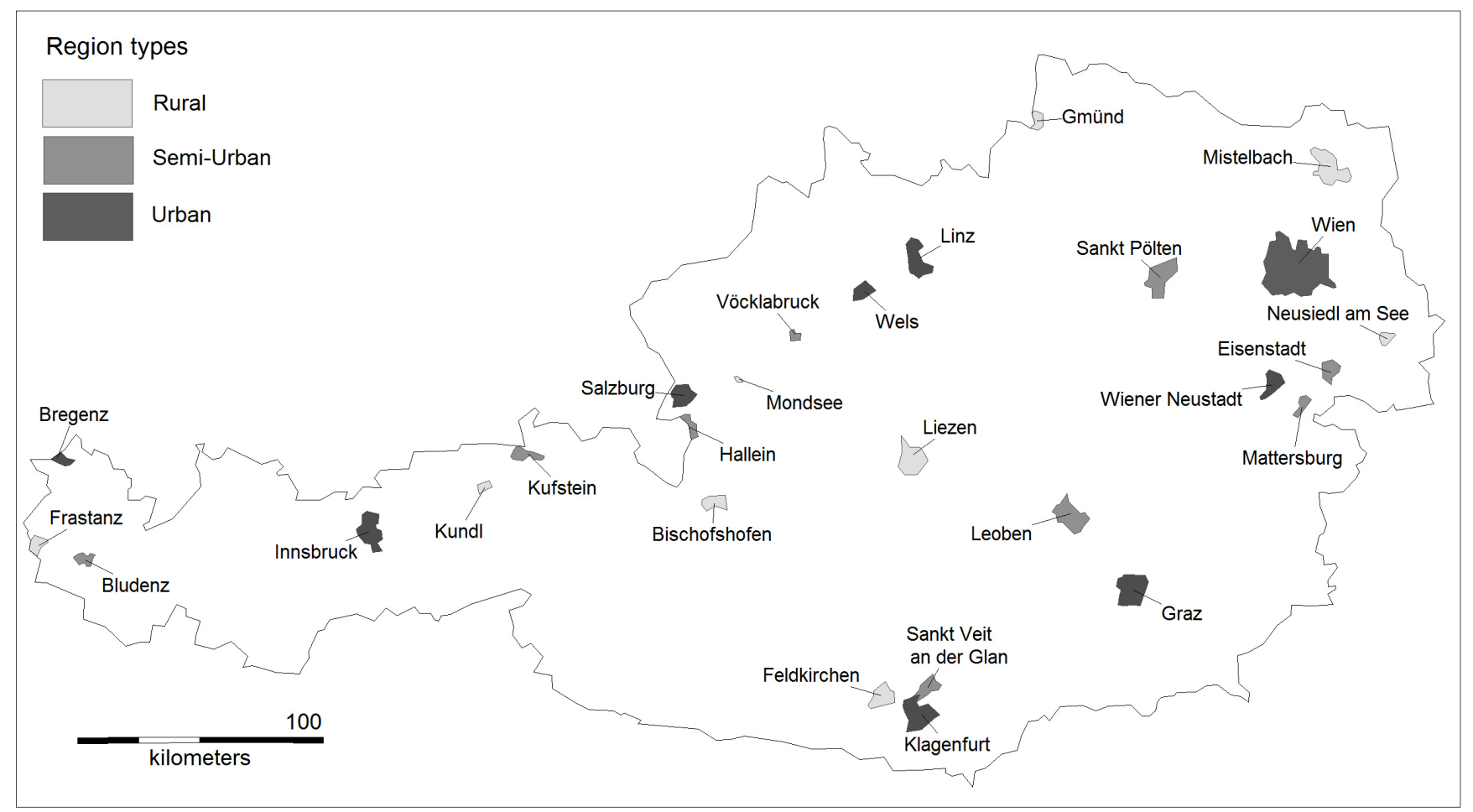


Figure 3. Finnish regions in the sample.

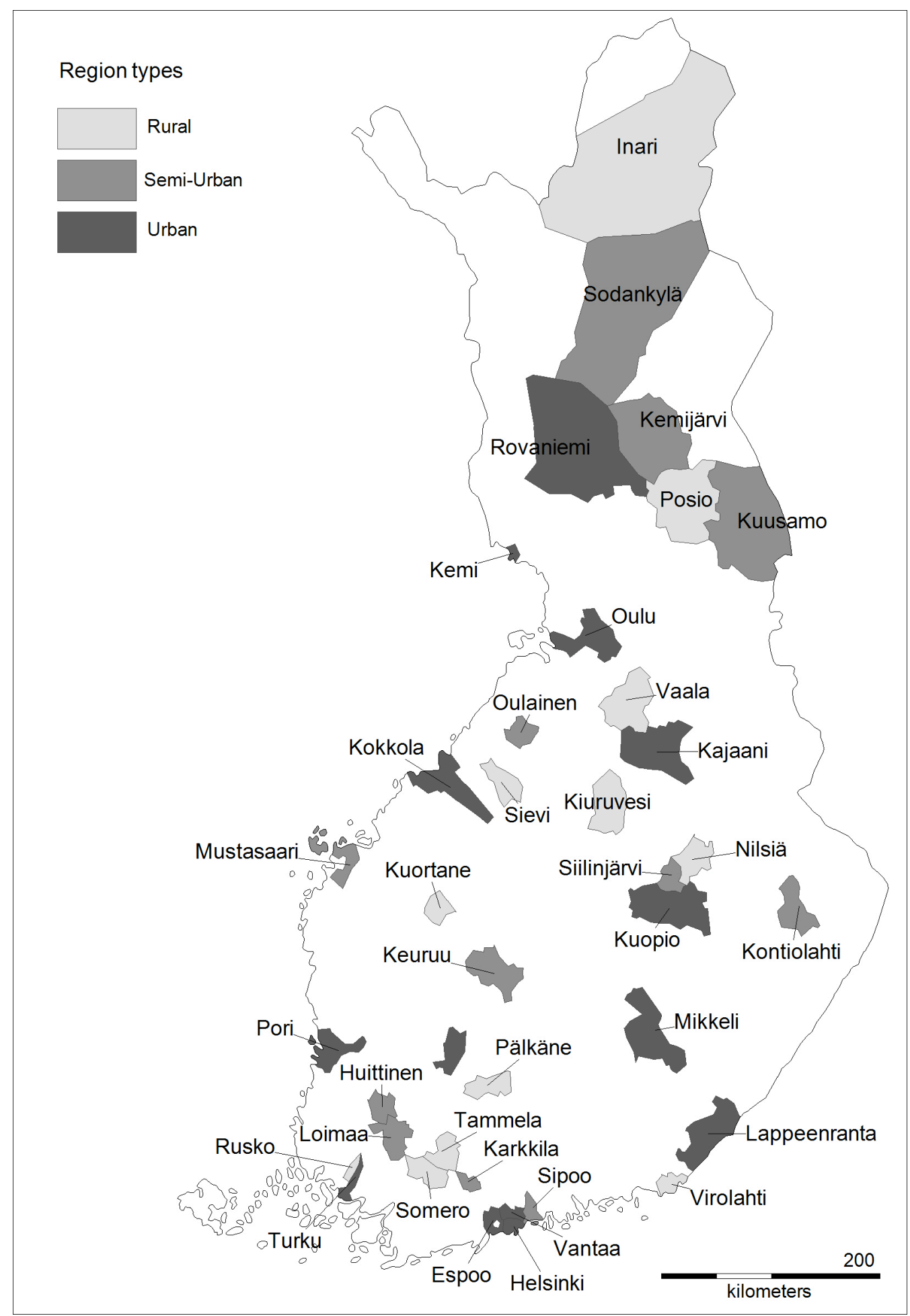

